\title{
BEBERAPA OPERASI DAN SIFAT-SIFAT PADA HIMPUNAN LEMBUT KABUR
}

\author{
RELI FIRMANENTI, NOVA NOLIZA BAKAR \\ Program Studi S1 Matematika, \\ Fakultas Matematika dan Ilmu Pengetahuan Alam, Universitas Andalas, \\ Kampus UNAND Limau Manis Padang, Indonesia. \\ email : relifirmanenti97@gmail.com,novanoliza@sci.unand.ac.id
}

Diterima 29 November 2019 Direvisi 3 Desember 2019 Dipublikasikan 12 Januari 2020

\begin{abstract}
Abstrak. Pada penelitian ini dibahas tentang operasi-operasi pada himpunan lembut kabur seperti gabungan himpunan lembut kabur, irisan himpunan lembut kabur, komplemen himpunan lembut kabur, algebraic sum himpunan lembut kabur, dan algebraic product himpunan lembut kabur. Kemudian, akan dibahas beberapa sifat pada himpunan lembut kabur yang terkait dengan operasi himpunan lembut kabur, serta adanya definisi mengenai monoid dan semiring yang terkait pada himpunan lembut kabur.

Kata Kunci: Himpunan lembut, himpunan kabur, himpunan lembut kabur, monoid, semiring
\end{abstract}

\section{Pendahuluan}

Masalah yang muncul di bidang teknik dan sosial sering melibatkan ketidakpastian. Dalam hal ini, metode klasik tidak selalu memadai untuk mengatasinya. Pada tahun 1999, Molodstov [5] memprakarsai suatu konsep himpunan lembut sebagai alat matematika baru untuk menangani masalah ketidakpastian. Pada tahun 2001, Maji dkk [7] memperkenalkan suatu konsep himpunan lembut kabur, operasi himpunan lembut kabur dan hukum De Morgan. Hasil ini selanjutnya direvisi dan dikembangkan oleh Ahmad dan Kharal [1].

Pada tahun 2011, Neog [10] mengemukakan gagasan baru mengenai komplemen himpunan lembut. Dan pada tahun 2012 Neog [8] juga mengemukakan gagasan baru mengenai komplemen himpunan lembut kabur. Kemudian pada tahun 2012, Borah [2] mengkaji beberapa operasi seperti gabungan dan irisan himpunan lembut kabur serta beberapa sifat pada himpunan lembut kabur.

Dalam makalah ini akan dikaji kembali beberapa sifat dari himpunan lembut kabur dengan menggunakan komplemen himpunan lembut kabur, yang diberikan oleh Neog [8], sebagaimana yang ada pada artikel Neog [8] dan Swarnambigai [12]. Disamping itu juga akan dibuktikan beberapa sifat-sifat lain terkait dengan himpunan lembut kabur tersebut.

${ }^{*}$ penulis korespondensi 
2. Tinjauan Pustaka

Pada bagian ini akan dijelaskan teori-teori yang akan digunakan dalam pembahasan, yaitu himpunan kabur, himpunan lembut, operasi himpunan kabur, operasi himpunan lembut, monoid, dan semiring.

Definisi 2.1. [14] Misalkan U adalah himpunan objek-objek. Suatu himpunan kabur $\mathcal{F}$ atas $U$ didefinisikan sebagai :

$$
\mathcal{F}=\left\{\left(x, \mu_{\mathcal{F}}(x)\right) \mid x \in U\right\} .
$$

dimana $\mu_{\mathcal{F}}: U \rightarrow[0,1]$ dan $\mu_{\mathcal{F}}(x)$ merupakan nilai keanggotaan dari $x$.

Definisi 2.2. [14] Suatu himpunan kabur $\mathcal{F}$ atas $U$ disebut himpunan kabur null, jika dan hanya jika $\mu_{\mathcal{F}}(x)=0, \forall x \in U$.

Definisi 2.3. [14] Suatu himpunan kabur $\mathcal{F}$ atas $U$ disebut himpunan kabur absolute, jika dan hanya jika $\mu_{\mathcal{F}}(x)=1, \forall x \in U$.

Definisi 2.4. [14] Untuk dua himpunan kabur $\mathcal{F}$ dan $\mathcal{G}$ atas $U$ dikatakan bahwa $\mathcal{F}$ adalah himpunan bagian kabur dari $\mathcal{G}$, ditulis $\mathcal{F} \subseteq \mathcal{G}$, jika $\mu_{\mathcal{F}}(x) \leq \mu_{\mathcal{G}}(x), \forall x \in U$.

Definisi 2.5. [14] Gabungan dari dua himpunan kabur $\mathcal{F}$ dan $\mathcal{G}$ dengan nilai keanggotaan masing-masing $\mu_{\mathcal{F}}(x)$ dan $\mu_{\mathcal{G}}(x)$ adalah himpunan kabur $\mathcal{H}$, ditulis sebagai $\mathcal{H}=\mathcal{F} \cup \mathcal{G}$, yang nilai keanggotaannya terkait dengan $\mathcal{F}$ dan $\mathcal{G}$ oleh :

$$
\mu_{\mathcal{H}}(x)=\max \left\{\mu_{\mathcal{F}}(x), \mu_{\mathcal{G}}(x)\right\}, x \in U .
$$

Definisi 2.6. [14] Irisan dari dua himpunan kabur $\mathcal{F}$ dan $\mathcal{G}$ dengan nilai keanggotaan masing-masing $\mu_{\mathcal{F}}(x)$ dan $\mu_{\mathcal{G}}(x)$ adalah himpunan kabur $\mathcal{H}$, ditulis sebagai $\mathcal{H}=\mathcal{F} \cap \mathcal{G}$, yang nilai keanggotaannya terkait dengan $\mathcal{F}$ dan $\mathcal{G}$ oleh :

$$
\mu_{\mathcal{H}}(x)=\min \left\{\mu_{\mathcal{F}}(x), \mu_{\mathcal{G}}(x)\right\}, x \in U .
$$

Definisi 2.7. [14] Misalkan $\mathcal{F}$ adalah suatu himpunan kabur atas $U$, maka komplemen dari himpunan kabur $\mathcal{F}$, ditulis sebagai $\mathcal{F}^{c}$, dan didefinisikan sebagai:

$$
\mu_{\mathcal{F}^{c}}(x)=1-\mu_{\mathcal{F}}(x) .
$$

Definisi 2.8. [13] Misalkan $\mathcal{F}$ dan $\mathcal{G}$ adalah dua himpunan kabur atas $U$, maka algebraic sum dari himpunan kabur $\mathcal{F}$ dan $\mathcal{G}$ ditulis sebagai $\mathcal{F} \oplus \mathcal{G}$, jika $\mu_{\mathcal{F} \oplus \mathcal{G}}(x)=$ $\mu_{\mathcal{F}}(x)+\mu_{\mathcal{G}}(x)-\mu_{\mathcal{F}}(x) \mu_{\mathcal{G}}(x)$.

Definisi 2.9. [13] Misalkan $\mathcal{F}$ dan $\mathcal{G}$ adalah dua himpunan kabur atas $U$, maka algebraic product dari himpunan kabur $\mathcal{F}$ dan $\mathcal{G}$ ditulis sebagai $\mathcal{F} \otimes \mathcal{G}$, jika $\mu_{\mathcal{F} \otimes \mathcal{G}}(x)=\mu_{\mathcal{F}}(x) \mu_{\mathcal{G}}(x)$.

Definisi 2.10. [5] Misalkan $U$ adalah himpunan objek-objek, E adalah suatu himpunan parameter dan $A \subseteq E$. Pasangan $(\mathcal{F}, A)$ disebut himpunan lembut atas $U$ jika dan hanya jika $\mathcal{F}$ adalah pemetaan dari $A$ ke himpunan dari semua himpunan bagian dari $U$ atau dapat disajikan dalam pasangan terurut:

$$
(\mathcal{F}, A)=\{(e, \mathcal{F}(e)) \mid e \in A, \mathcal{F}(e) \in P(U)\},
$$


dimana $\mathcal{F}: A \rightarrow P(U)$.

Definisi 2.11. [6] Suatu himpunan lembut $(\mathcal{F}, A)$ atas $U$ disebut himpunan lembut null, ditulis sebagai $\varphi$, jika $\mathcal{F}(\alpha)=\varphi, \forall \alpha \in A$.

Definisi 2.12. [6] Suatu himpunan lembut $(\mathcal{F}, A)$ atas $U$ disebut himpunan lembut absolute, ditulis sebagai $U$, jika $\mathcal{F}(\alpha)=U, \forall \alpha \in A$.

Definisi 2.13. [6] Untuk dua himpunan lembut $(\mathcal{F}, A)$ dan $(\mathcal{G}, B)$ atas $U$, dikatakan bahwa $(\mathcal{F}, A)$ adalah himpunan bagian lembut dari $(\mathcal{G}, B)$, jika:

(i) $A \subseteq B$,

(ii) $\forall \alpha \in A, \mathcal{F}(\alpha) \subseteq \mathcal{G}(\alpha)$ dan ditulis sebagai $(\mathcal{F}, A) \subseteq(\mathcal{G}, B)$.

Definisi 2.14. [6] Gabungan dari dua himpunan lembut $(\mathcal{F}, A)$ dan $(\mathcal{G}, B)$ atas $U$, adalah himpunan lembut $(\mathcal{H}, C)$, dimana $C=A \cup B$ dan $\forall \alpha \in C$,

$$
\mathcal{H}(\alpha)=\left\{\begin{array}{l}
\mathcal{F}(\alpha) \quad, \text { jika } \quad \alpha \in A-B \\
\mathcal{G}(\alpha) \quad, \text { jika } \quad \alpha \in B-A \\
\mathcal{F}(\alpha) \cup \mathcal{G}(\alpha), \text { jika } \alpha \in A \cap B .
\end{array}\right.
$$

Atau ditulis sebagai

$$
(\mathcal{H}, C)=(\mathcal{F}, A) \tilde{\cup}(\mathcal{G}, B) .
$$

Definisi 2.15. [6] Irisan dari dua himpunan lembut atas $U(\mathcal{F}, A)$ dan $(\mathcal{G}, B)$ adalah himpunan lembut $(\mathcal{H}, C)$, dimana $C=A \cap B$, dan $\forall \alpha \in C, \mathcal{H}(\alpha)=\mathcal{F}(\alpha) \cap$ $\mathcal{G}(\alpha)$, atau ditulis sebagai

$$
(\mathcal{H}, C)=(\mathcal{F}, A) \tilde{\cap}(\mathcal{G}, B) .
$$

Definisi 2.16. [10] Komplemen dari himpunan lembut $(\mathcal{F}, A)$ ditulis sebagai $(\mathcal{F}, A)^{c}$, dan didefinisikan sebagai:

$$
(\mathcal{F}, A)^{c}=\left(\mathcal{F}^{c}, A\right)
$$

dimana $\mathcal{F}^{c}: A \rightarrow P(U)$ adalah suatu pemetaan yang dinyatakan sebagai $\mathcal{F}^{c}(\alpha)=$ $[\mathcal{F}(\alpha)]^{c}$ untuk setiap $\alpha \in A$.

Definisi 2.17. [4] Suatu himpunan $M$ dengan operasi biner $\circ$ disebut semigrup, jika $(a \circ b) \circ c=a \circ(b \circ c), \forall a, b, c \in M$. Suatu semigrup $(M, \circ)$ disebut monoid, jika $\exists e \in M \ni e \circ a=a \circ e=a, \forall a \in M$, dimana elemen e disebut identitas untuk operasi biner $\circ$. Jika operasi biner $\circ$ bersifat komutatif, maka disebut monoid komutatif.

Definisi 2.18. [3] Himpunan tak kosong $M$ dengan dua operasi biner "+" dan "." (penjumlahan atau perkalian) disebut Semiring, jika memenuhi kondisi berikut:

(1) $(M,+)$ adalah suatu monoid komutatif,

(2) $(M, \cdot)$ adalah suatu semigrup, dan

(3) (i) $a \cdot(b+c)=(a \cdot b)+(a \cdot c), \forall a, b, c \in M$, dan

(ii) $(a+b) \cdot c=(a \cdot c)+(b \cdot c), \forall a, b, c \in M$. 


\section{Hasil Utama}

Pada bagian ini akan dijelaskan tentang definisi-definisi, operasi-operasi pada himpunan lembut kabur, dan beberapa sifat himpunan lembut kabur.

Definisi 3.1. [7] Misalkan $U$ adalah himpunan objek-objek, E adalah suatu himpunan parameter dan $A \subseteq E$. Pasangan $(\mathcal{F}, A)$ disebut himpunan lembut kabur atas $U$ jika dan hanya jika $\mathcal{F}$ suatu pemetaan dari $A$ ke $\tilde{P}(U)$. Atau dapat dinyatakan sebagai:

$$
\begin{aligned}
(\mathcal{F}, A) & =\{(\alpha, \mathcal{F}(\alpha)) \mid \alpha \in A, \mathcal{F}(\alpha) \in \tilde{P}(U)\} \\
& =\left\{\left(\alpha,\left\{\left(x, \mu_{\mathcal{F}(\alpha)}(x)\right) \mid x \in U\right\}\right) \mid \forall \alpha \in A\right\}
\end{aligned}
$$

dimana $\mathcal{F}: A \rightarrow \tilde{P}(U)$ dan $\tilde{P}(U)$ adalah kumpulan dari himpunan-himpunan kabur atas $U$.

Definisi 3.2. [2] Misalkan $U$ adalah himpunan objek-objek dan E adalah himpunan parameter. Pasangan $[U, E]$ menyatakan kumpulan dari semua himpunan lembut kabur pada $U$, dengan parameter dari $E$, dan disebut dengan kelas lembut kabur.

Definisi 3.3. [7] Suatu himpunan lembut kabur $(\mathcal{F}, A)$ atas $U$ disebut dengan himpunan lembut kabur null yang ditulis sebagai $(\varphi, A)$, jika $\forall \alpha \in A, \mathcal{F}(\alpha)$ adalah himpunan kabur null dari $U$, dimana $\mu_{\mathcal{F}}(x)=0, \forall x \in U$.

Definisi 3.4. [7] Suatu Himpunan lembut kabur $(\mathcal{F}, A)$ atas $U$ disebut dengan himpunan lembut kabur absolute yang ditulis sebagai $(U, A)$, jika $\forall \alpha \in A, \mathcal{F}(\alpha)$ adalah himpunan kabur absolute dari $U$, dimana $\mu_{\mathcal{F}}(x)=1, \forall x \in U$.

Definisi 3.5. [7] Untuk dua himpunan lembut kabur $(\mathcal{F}, A)$ dan $(\mathcal{G}, B)$ dalam kelas lembut kabur $[U, E]$, dikatakan bahwa $(\mathcal{F}, A)$ adalah himpunan bagian lembut kabur $\operatorname{dari}(\mathcal{G}, B)$, jika:

(i) $A \subseteq B$,

(ii) $\forall \alpha \in A, \mathcal{F}(\alpha) \subseteq \mathcal{G}(\alpha)$ dan ditulis sebagai $(\mathcal{F}, A) \subseteq(\mathcal{G}, B)$.

Definisi 3.6. [7] Gabungan dari dua himpunan lembut kabur $(\mathcal{F}, A)$ dan $(\mathcal{G}, B)$ dalam kelas lembut kabur $[U, E]$, adalah suatu himpunan lembut kabur $(\mathcal{H}, C)$, dimana $C=A \cup B$ dan $\forall \alpha \in C$,

$$
\mathcal{H}(\alpha)=\left\{\begin{array}{l}
\mathcal{F}(\alpha) \quad, \text { jika } \quad \alpha \in A-B \\
\mathcal{G}(\alpha), \text { jika } \quad \alpha \in B-A \\
\mathcal{F}(\alpha) \cup \mathcal{G}(\alpha), \text { jika } \quad \alpha \in A \cap B
\end{array}\right.
$$

dan ditulis sebagai

$$
(\mathcal{H}, C)=(\mathcal{F}, A) \tilde{\cup}(\mathcal{G}, B) .
$$

Definisi 3.7. [1] Misalkan $(\mathcal{F}, A)$ dan $(\mathcal{G}, B)$ adalah dua himpunan lembut kabur dalam kelas lembut kabur $[U, E]$ dengan $A \cap B \neq \emptyset$. Maka irisan dari dua himpunan 
lembut kabur $(\mathcal{F}, A)$ dan $(\mathcal{G}, B)$ dalam kelas lembut kabur $[U, E]$, adalah suatu himpunan lembut kabur $(\mathcal{H}, C)$, dimana $C=A \cap B$ dan $\forall \alpha \in C, \mathcal{H}(\alpha)=\mathcal{F}(\alpha) \cap \mathcal{G}(\alpha)$, atau ditulis sebagai

$$
(\mathcal{H}, C)=(\mathcal{F}, A) \tilde{\cap}(\mathcal{G}, B) .
$$

Definisi 3.8. [8] Komplemen dari himpunan lembut kabur $(\mathcal{F}, A)$ ditulis sebagai $(\mathcal{F}, A)^{c}$, dan didefinisikan sebagai:

$$
(\mathcal{F}, A)^{c}=\left(\mathcal{F}^{c}, A\right)
$$

dimana, $\mathcal{F}^{c}: A \rightarrow P(U)$ adalah suatu pemetaan yang dinyatakan sebagai $\mathcal{F}^{c}(\alpha)=$ $[\mathcal{F}(\alpha)]^{c}, \forall \alpha \in A$.

Definisi 3.9. Misalkan $(\mathcal{F}, A)$ dan $(\mathcal{G}, A)$ adalah dua himpunan lembut kabur atas $U$ dengan parameter yang sama, maka algebraic sum dari himpunan lembut kabur $(\mathcal{F}, A)$ dan $(\mathcal{G}, A)$ ditulis sebagai $(\mathcal{F}, A) \oplus(\mathcal{G}, A)$, dan didefinisikan sebagai:

$$
(\mathcal{F}, A) \oplus(\mathcal{G}, A)=\left\{\left(\alpha,\left\{\left(x, \mu_{\mathcal{F}(\alpha) \oplus \mathcal{G}(\alpha)}(x)\right) \mid x \in U\right\}\right) \mid \forall \alpha \in A\right\}
$$

dimana, $\mu_{\mathcal{F}(\alpha) \oplus \mathcal{G}(\alpha)}(x)=\mu_{\mathcal{F}(\alpha)}(x)+\mu_{\mathcal{G}(\alpha)}(x)-\mu_{\mathcal{F}(\alpha)}(x) \mu_{\mathcal{G}(\alpha)}(x)$.

Definisi 3.10. Misalkan $(\mathcal{F}, A)$ dan $(\mathcal{G}, A)$ adalah dua himpunan lembut kabur atas $U$ dengan parameter yang sama, maka algebraic product dari himpunan lembut $\operatorname{kabur}(\mathcal{F}, A)$ dan $(\mathcal{G}, A)$ ditulis sebagai $(\mathcal{F}, A) \otimes(\mathcal{G}, A)$, dan didefinisikan sebagai:

$$
(\mathcal{F}, A) \otimes(\mathcal{G}, A)=\left\{\left(\alpha,\left\{\left(x, \mu_{\mathcal{F}(\alpha) \otimes \mathcal{G}(\alpha)}(x)\right) \mid x \in U\right\}\right) \mid \forall \alpha \in A\right\}
$$

$\operatorname{dimana}, \mu_{\mathcal{F}(\alpha) \otimes \mathcal{G}(\alpha)}(x)=\mu_{\mathcal{F}(\alpha)}(x) \mu_{\mathcal{G}(\alpha)}(x)$.

Proposisi 3.11. [12] Misalkan diberikan himpunan lembut kabur $(\mathcal{F}, A)$ atas $U$, maka berlaku:

(1) $(\varphi, A)^{c}=(U, A)$

(2) $(U, A)^{c}=(\varphi, A)$

(3) $(\mathcal{F}, A) \tilde{\cup}(\varphi, A)=(\mathcal{F}, A)$

(4) $(\mathcal{F}, A) \tilde{\cup}(U, A)=(U, A)$

(5) $(\mathcal{F}, A) \tilde{\cap}(\varphi, A)=(\varphi, A)$

(6) $(\mathcal{F}, A) \tilde{\cap}(U, A)=(\mathcal{F}, A)$

(7) $(\mathcal{F}, A) \tilde{\cup}(\varphi, B)=(\mathcal{F}, A)$, jika dan hanya jika $B \subseteq A$

(8) $(\mathcal{F}, A) \tilde{\cup}(U, B)=(U, B)$, jika dan hanya jika $A \subseteq B$

(9) $(\mathcal{F}, A) \tilde{\cap}(\varphi, B)=(\varphi, A \cap B)$

(10) $(\mathcal{F}, A) \tilde{\cap}(U, B)=(\mathcal{F}, A \cap B)$

Berikut ini akan diberikan sifat-sifat pada himpunan lembut kabur mengenai komutatif, asosiatif dan distributif.

Proposisi 3.12. Misalkan sebarang himpunan lembut kabur $(\mathcal{F}, A),(\mathcal{G}, A)$, dan $(\mathcal{H}, A)$ atas $U$, maka berlaku:

(1) Komutatif terhadap gabungan dan irisan, yakni:

(i) $(\mathcal{F}, A) \tilde{\cup}(\mathcal{G}, A)=(\mathcal{G}, A) \tilde{\cup}(\mathcal{F}, A)$ 
(ii) $(\mathcal{F}, A) \tilde{\cap}(\mathcal{G}, A)=(\mathcal{G}, A) \tilde{\cap}(\mathcal{F}, A)$

(2) Asosiatif terhadap gabungan dan irisan, yakni:

(i) $(\mathcal{F}, A) \tilde{\cup}((\mathcal{G}, A) \tilde{\cup}(\mathcal{H}, A))=((\mathcal{F}, A) \tilde{\cup}(\mathcal{G}, A)) \tilde{\cup}(\mathcal{H}, A)$

(ii) $(\mathcal{F}, A) \tilde{\cap}((\mathcal{G}, A) \tilde{\cap}(\mathcal{H}, A))=((\mathcal{F}, A) \tilde{\cap}(\mathcal{G}, A)) \tilde{\cap}(\mathcal{H}, A)$

(3) Distributif, yakni:

(i) $(\mathcal{F}, A) \tilde{\cup}((\mathcal{G}, A) \tilde{\cap}(\mathcal{H}, A)=((\mathcal{F}, A) \tilde{\cup}(\mathcal{G}, A)) \tilde{\cap}((\mathcal{F}, A) \tilde{\cup}(\mathcal{H}, A))$

(ii) $((\mathcal{F}, A) \tilde{\cap}(\mathcal{G}, A) \tilde{\cup}(\mathcal{H}, A)=((\mathcal{F}, A) \tilde{\cap}(\mathcal{H}, A)) \tilde{\cup}((\mathcal{G}, A) \tilde{\cap}(\mathcal{H}, A))$

Akibat 3.13. Kumpulan dari himpunan-himpunan lembut kabur atas $U$ merupakan suatu monoid komutatif baik terhadap operasi gabungan maupun terhadap operasi irisan dan merupakan semiring terhadap gabungan (sebagai operasi " +") dan irisan (sebagai operasi "×").

Berikut ini akan dibuktikan sifat-sifat pada himpunan lembut kabur atas $U$ mengenai algebraic sum dan algebraic product.

Proposisi 3.14. Misalkan terdapat sebarang himpunan lembut kabur $(\mathcal{F}, A),(\mathcal{G}, A)$ dan $(\mathcal{H}, A)$ atas $U$, maka berlaku:

(1) $(\mathcal{F}, A) \oplus(\varphi, A)=(\mathcal{F}, A)$

(2) $(\mathcal{F}, A) \oplus(U, A)=(U, A)$

(3) $(\mathcal{F}, A) \otimes(\varphi, A)=(\varphi, A)$

(4) $(\mathcal{F}, A) \otimes(U, A)=(\mathcal{F}, A)$

(5) Bersifat komutatif terhadap $\oplus$ dan $\otimes$, yakni:

(i) $(\mathcal{F}, A) \oplus(\mathcal{G}, A)=(\mathcal{G}, A) \oplus(\mathcal{F}, A)$

(ii) $(\mathcal{F}, A) \otimes(\mathcal{G}, A)=(\mathcal{G}, A) \otimes(\mathcal{F}, A)$

(6) Bersifat asosiatif terhadap $\oplus$ dan $\otimes$, yakni:

(i) $(\mathcal{F}, A) \oplus((\mathcal{G}, A) \oplus(\mathcal{H}, A))=((\mathcal{F}, A) \oplus(\mathcal{G}, A)) \oplus(\mathcal{H}, A)$

(ii) $(\mathcal{F}, A) \otimes((\mathcal{G}, A) \otimes(\mathcal{H}, A))=((\mathcal{F}, A) \otimes(\mathcal{G}, A)) \otimes(\mathcal{H}, A)$

Akibat 3.15. Kumpulan dari himpunan-himpunan lembut kabur atas $U$ merupakan suatu monoid komutatif terhadap operasi $\oplus$ dan monoid komutatif terhadap operasi $\otimes$.

Proposisi 3.16. [12] Untuk himpunan lembut kabur $(\mathcal{F}, A)$ dan $(\mathcal{G}, B)$ atas $U$, berlaku:

(1) $((\mathcal{F}, A) \tilde{\cup}(\mathcal{G}, B))^{c} \tilde{\subseteq}(\mathcal{F}, A)^{c} \tilde{\cup}(\mathcal{G}, B)^{c}$

(2) $((\mathcal{F}, A) \tilde{\cap}(\mathcal{G}, B))^{c} \tilde{\subseteq}(\mathcal{F}, A)^{c} \tilde{\cap}(\mathcal{G}, B)^{c}$

Proposisi 3.17. [12] (De Morgan Inclusions) Untuk himpunan lembut kabur $(\mathcal{F}, A)$ dan $(\mathcal{G}, B)$ atas $U$, berlaku:

(1) $(\mathcal{F}, A)^{c} \tilde{\cap}(\mathcal{G}, B)^{c} \subseteq((\mathcal{F}, A) \tilde{\cup}(\mathcal{G}, B))^{c}$

(2) $((\mathcal{F}, A) \tilde{\cap}(\mathcal{G}, B))^{c} \tilde{\subseteq}(\mathcal{F}, A)^{c} \tilde{\cup}(\mathcal{G}, B)^{c}$ 
Proposisi 3.18. [12] (De Morgan Laws)

Untuk himpunan lembut kabur $\left(\mathcal{F}_{1}, A\right),\left(\mathcal{F}_{2}, A\right), \ldots,\left(\mathcal{F}_{n}, A\right)$ atas $U$, berlaku:

(1) $\left(\left(\mathcal{F}_{1}, A\right) \tilde{\cup}\left(\mathcal{F}_{2}, A\right) \tilde{\cup} \ldots \tilde{\cup}\left(\mathcal{F}_{n}, A\right)\right)^{c}=\left(\mathcal{F}_{1}, A\right)^{c} \tilde{\cap}\left(\mathcal{F}_{2}, A\right)^{c} \tilde{\cap} \ldots \tilde{\cap}\left(\mathcal{F}_{n}, A\right)^{c}$

(2) $\left(\left(\mathcal{F}_{1}, A\right) \tilde{\cap}\left(\mathcal{F}_{2}, A\right) \tilde{\cap} \ldots \tilde{\cap}\left(\mathcal{F}_{n}, A\right)\right)^{c}=\left(\mathcal{F}_{1}, A\right)^{c} \tilde{\cup}\left(\mathcal{F}_{2}, A\right)^{c} \tilde{\cup} \ldots \tilde{\cup}\left(\mathcal{F}_{n}, A\right)^{c}$

\section{Kesimpulan}

Dalam Neog [8] telah dikemukakan suatu gagasan baru mengenai komplemen himpunan lembut kabur yang didefinisikan sebagai $(\mathcal{F}, A)^{c}=\left(\mathcal{F}^{c}, A\right)$, dimana, $\mathcal{F}^{c}: A \rightarrow P(U)$ adalah suatu pemetaan yang dinyatakan sebagai $\mathcal{F}^{c}(\alpha)=[\mathcal{F}(\alpha)]^{c}$, $\forall \alpha \in A$.

Operasi-operasi yang digunakan pada himpunan lembut kabur adalah gabungan himpunan lembut kabur, irisan himpunan lembut kabur, komplemen himpunan lembut kabur, algebraic sum himpunan lembut kabur dan algebraic product himpunan lembut kabur. Berdasarkan operasi-operasi yang digunakan pada himpunan lembut kabur berlaku sifat-sifat pada himpunan lembut kabur yaitu: sifat komutatif terhadap operasi gabungan, irisan, algebraic sum, dan algebraic product, sifat assosiatif terhadap operasi gabungan, irisan, algebraic sum, dan algebraic product, sifat distributif terhadap operasi gabungan dan irisan, serta sifat De Morgan Laws dan De Morgan Inclusions.

\section{Ucapan Terima Kasih}

Penulis mengucapkan terima kasih kepada Bapak Admi Nazra, Ibu Yanita, Bapak Dodi Devianto dan Bapak Yudiantri Asdi yang telah memberikan masukan dan saran sehingga makalah ini dapat diselesaikan dengan baik.

\section{Daftar Pustaka}

[1] Ahmad, B. dan Athar Kharal. 2009. On Fuzzy Soft Sets. Advances in Fuzzy Systems. Vol. 9, hal. $1-6$

[2] Borah, M. dkk. 2012. A Study On Some Operations of Fuzzy Soft Sets. International Journal of Modern Engineering Research. Vol. 2, hal 219 - 225

[3] Dale, L. 1976. Monic and Monic-free Ideals in a Polynomial Semiring. PAMS. Vol. 56 , pp. $45-50$

[4] Lax, R.F. 1991. Modern Algebra and Discrete Structures. New York: Louisiana State University.

[5] Molodtsov, D. 1999. Soft Set Theory First Result. Computers and Mathematics with Applications. Vol. 37, No. (4-5), pp. $19-31$

[6] Maji P. K. dan A. R Roy. 2003. Soft Set Theory. Computers and Mathematics with Aplications. Vol. 45, pp. $555-562$

[7] Maji P. K, R. dkk. 2001. Fuzzy Soft Sets. Journal of Fuzzy Mathematics. Vol. 9, No. (3), pp. $589-602$

[8] Neog, T.J dan D. K. Sut. 2012. On Fuzzy Soft Complement dan Related Properties. Accepted for publication in International Journal of Energy, Information and Communications (IJEIC) 
[9] Neog, T.J dan D. K. Sut. 2011. On Union and Intersection of Fuzzy Soft Sets. International Journal Computer Applications. Vol. 2, No. (5), pp. 1160 - 1176

[10] Neog, T.J dan D. K. Sut. 2011. A New Approach to The Theory of Soft Sets. International Journal Computer Applications. Vol. 32, No. (2), pp. $1-6$

[11] Pei, D. dan D. Miao. 2005. From Soft Sets to Information Systems. In Proceedings of the International Conference on Granular Computing. Vol. 2, pp. 617 $-621$

[12] Swarnambigai, M. dan K. Geetha . 2017. Some Operations on Fuzzy Soft Sets Theory. International Journal of Advance Research and Innovative Ideas in Education (IJARIIE). Vol. 3, pp. 1628 - 1637

[13] Zadeh, L. A. 1968. Probability Measures of Fuzzy Events . Journal of Mathematical Analysis and Applications. Vol. 23, pp. $421-427$

[14] Zadeh, L. A. 1965. Fuzzy Sets. Information and Control. Vol. 8, No. 3 pp. 338 $-353$ 